\title{
Empirical Study on Impact of New In- formation Communication Technology on Digital Divides:Beijing and Shanghai
}

\author{
Yo Xiaobin Lu', Xi Meng ${ }^{1}$ (correspondent), Jing Guo ${ }^{1}$, Wei Huang ${ }^{3}$ \\ ${ }^{1}$ School of Information Resource Management, Renmin University of China \\ ${ }^{2}$ Department of Public Security Intelligence, People's Public Security University of \\ China \\ ${ }^{3}$ Department of Geography, University of Wisconsin-Milwaukee
}

\begin{abstract}
With the diffusion of mobile devices and Internet, the acquisition of information becomes more convenient and easily accessible to different walks of life. As such, the digital divide has evolved from unequal access to Internet to deeper level reflecting the gap of network knowledge and skills. In this article, the authors focus on the exploring of the influence of new information and communication technology (ICT) on deep digital divide of different social classes, collecting various samples from Beijing and Shanghai, and conducting an empirical research on the deep digital divide in these regions. Questionnaires and interviews are conducted on different social classes in order to retrieve related information and understand the effort of applying related policies and subsequences of mitigating digital divide. By applying dynamic statistical analysis on feedback data, related mechanism, modes as well as general principles reflecting the influence of new information and communication technology on deep digital divide are revealed in this study.
\end{abstract}

Key words: deep digital divide, new ICT, empirical research, knowledge gap

\section{Introduction}

The information and communication technology (ICT) is a technology that provides access to information through telecommunication. Nowadays, with the rapid development of hardware and software, ICT has been characterized primarily by Internet, wireless network, mobile phone and other communication mediums (Timothy and Manuel, 1995). It is widely acknowledged that the access to information and communication technology would bring about tremendous opportunities of information exchange and interaction leading an improvement of living standards and social welfare (Sanjeev and Frederick, 2005). Such opportunities include the education, health and employment (Çiğdem, Bilge and Erman, 2009). In addition, it is also associated with making individual competitive and productive (María and Ana, 2011).

Despite many potential benefits the development, ICT do generate many side effects that cannot be neglected. The digital divide is one of the prominent examples. Initial approach of the digital divide focused primarily on the inequal access to the Internet and personal computers. The second level of digital divide, however, looked deeper into the inequal usage of 
Internet on the basis of universal accessibility (Attewell, 2001).

For decades, the first and second level of the digital divide were seen as centerpieces for most studies and researches. There was no exception in digital divide study of China. The deep digital divide specifically the third level of digital divide in urban area of China was barely examined in previous studies. Given the absence of verifiable and detailed information on this particular case, our study attempts to investigate the influence of new ICT on the third digital divide with the specific aspect of knowledge gap. To meet this goal, the study will first utilize the data collected from questionnaires and interviews among different social class of Beijing and Shanghai. Then, the link between the adoption of new ICT and knowledge disparity will be examined and followed by a statistic analysis of different factors that influence the knowledge gap. Finally, a conclusion was made to articulate our findings.

\section{Background}

\subsection{Knowledge gap and the third level of digital divide}

The knowledge gap hypothesis $(\mathrm{KGH})$ was introduced by Phillip Tichenor, George Donohue and Clarice Olien in 1970. In their article (Tichenor, Donohue, and Olien, 1970), the hypothesis was formulated based on the assumptions that level of education and socio-economic status are directly related and that the idea of the KGH has been "implicit" in the mass communication literature without having explicitly been stated (Bunz, 2009). This hypothesis gave a consideration of time and was based on mass communication lasting over 20 years. It argued that that mass media targeted the people who are least in need of information, thus contradicted with the generally accepted be- lief that mass media will reach the public easily and keep them well informed as a result.

As the newly emerging mass media, the Internet has several advantages over traditional media. The influence of new media became a new topic and the third level of digital divide was linked with the knowledge gap in some researches (Bucy, 2000; DiMaggio et al., 2001; Kingsley and Anderson, 1998; Van Dijk and Hacker,2003). However, extending the KGH to all mass media is criticized as a misplaced or premature approach. In addition, the amount of knowledge does not necessarily grow proportionally with the knowledge already gained even if the recipients are well informed. The celling effect in the upper group (Katzman, 1974; Ettema and Kline, 1977) constrained the information flow but narrowed the knowledge gap consequently. As a result, the information poor will eventually catch up with the information rich given enough time and effort.

\subsection{The digital divide in Beijing and Shanghai}

Benefiting from the rapid economic growth, the development of ICT in China had an exponential increase in the last decade. Within the total 538 million Internet users, 388 million of them visited the Internet via cell phones as of June, 2012 (CNNIC, 2012). Different from previous reports that always highlighted the domination of PC access to Internet, this report present a surprising fact that for the first time ever, the mobile Internet users in China outnumbers those user with PC and other devices.

Being the economic developed regions, Beijing and Shanghai have a leading Internet penetration rate over the average national level of $39.9 \%$, ranking No.1 $(70.3 \%)$ and No.2 (66.2\%) in 2012, respectively (CNNIC, 2012). In addition, the penetration rate of Apple's Mobile 
device with internet accessing function (iPhone and iPad, exclusive of iPod touch) in Beijing and Shanghai reached 11.1\% and $9.4 \%$ by the end of 2011 , respectively (Morgan Stanley AlphaWise, Umeng, Flurry Analytics, insidemobileapps.com computerworld.com, Apple, Stenvall Skoeld \& Company analysis, 2011).

Owing to the fast development of ICT, the first level of digital divide in terms of Internet access in Beijing and Shanghai has been significantly narrowed in recent years. Nonetheless, with the balance of Internet accessibility shifted, it becomes increasingly important to reexamine the situation of the digital divide, necessitating an insight inspection on two specific topics: whether the third divide exists and how does it exist among different social classes in Beijing and Shanghai.

\section{Methodology}

\subsection{Research hypothesis}

The research will investigate the Internet knowledge gap among different users, specifically their knowledge about Internet searching techniques via cell phones. In order to explore how the network access and network usage influence the network knowledge, the following hypotheses were developed.

Hypothesis 1: The use of Internet has more influence on Internet knowledge than Internet access via cell phones.

Hypothesis 2: Traditional factors such as age, gender, education degree, income, and occupation are still account for the third digital divide considerably as they do for the first divide.

Hypothesis 3: There are no significant difference of Internet knowledge level between Beijing and Shanghai.

\subsection{Survey}

The object of the survey was selected as the neighborhood of 5 different universi- ties in Beijing and Shanghai. Each neighborhood lies within a radius of 1 kilometer around the campus of each university. In Beijing, a total of 460 questionnaires were issued, 260 were retrieved with a valid response rate of $56.5 \%$. Whereas in Shanghai, a total of 480 questionnaires were issued, 258 were retrieved with a valid response rate of $53.8 \%$. For those questions that will be recorded by the computer, items were arranged on a 5point Likert scale from $1=$ strongly disagree to $5=$ strongly agree. Then, after collecting the survey data, the original survey data was input into SPSS 19.0 software for the following statistical analysis.

Dependent variable: The dependent variable in this study was set as Internet Knowledge on search technique on mobile phone.

Independent variables: This a group that contains multiple variables, including Internet access, Internet usage, media choice, and those variables that predominantly affect the first digital divide, such as Age, gender, income and education degree.

Age, gender, income and education degree were integrated as Population variable. The users' choice between traditional media and Internet was a variable that reflect personal tendency of seeking information when facing different options from different media.

In summary, the setting of the variables was meant to find the existence of Gaps in access to the Internet and Gaps in use of the Internet, as well as how these two gaps affect Gaps in knowledge of the Internet, which is the target of this study.

\section{Results}

\subsection{Reliability Analysis}

Cronbach's coefficient alpha was calculated for Net accessibility, Net usage and Network knowledge variables by using 
SPSS software. The item inside each variable was described by an initial abbreviation plus a number attachment. The result (see Table 1.) demonstrated acceptable reliability with a coefficient alpha more than 0.7 and higher Corrected Item-Total Correlation (CITC) of more than 0.5. Therefore, it can be concluded that the questionnaire used for the survey has an overall excellent internal consistency.

\subsection{Regression Analysis}

To identify the factors that affect Internet knowledge level, the linear regression was conducted in the group of Beijing and Shanghai, respectively.

According to Table 2, the main contributors of Internet knowledge in Beijing are accessing Internet via cell phone (NAC 2), followed by online frequency (NUS 3), information about product price (MCF 4) and merchant (MCF 5), and topic about books (MCF 2). The scenario in Shanghai, however, is that content oriented net access (NAC 8) appear to be the major predicators, followed by accessing Internet via cell phone (NAC 2), years online (NUS 1), information about product price (MCF 4) and topic about ticket (Movies, match or other shows) (MCF 3). The minor differences between the two regions could possible owe to different search interests among different users. Specifically, the favor of book searching in Beijing and the favor of tickets searching in Shanghai could be one possible reason behind the different search habits among the two regions.

\subsection{Paired-samples $T$ test}

In order to examine the difference of Internet knowledge level between Bejing (BJ) and Shanghai (SH), firstly the basic descriptive table was created (Table 3), and then a paired samples $\mathrm{T}$ test was conducted. The score on Internet knowledge from the questionnaire was compared and contrast with each other. The significant test at 2-tailed level in Table 4 suggested that there no significant difference of Internet knowledge level between the two cities. This provides evidence for Hypothesis 2 .

\subsection{Verification of the hypothesis}

Hypothesis 1: The use of Internet has more influence on Internet knowledge than Internet access via cell phones. This hypothesis was rejected due to the fact that the standardized coefficients of Table 2 in the section of net access are higher than those in the net usage section, meaning that they are more significant in affecting the mobile net knowledge.

Hypothesis 2: Traditional factors such as age, gender, education degree, income, and occupation still account for the third digital divide considerably as they do for the first divide. These factors, unfortunately, are not necessarily the predominant factors as they are in the first level. Based on the data reported in Table 2, for either in Beijing and Shanghai, there isn't any factor in the section of population variable appears to be significant. Therefore, this hypothesis is rejected.

Hypothesis 3: There are no significant difference of Internet knowledge level between Beijing and Shanghai. The result from Table 4 indicated that the respondents in the two regions had a similar performance on the Internet knowledge survey. Consequently, hypothesis 3 is accepted.

\subsection{The third digital divide in different social class}

As shown in Table 5, the third digital divide has a huge difference among different users. Despite the overall high percentage in the subject pool, students' average performances are not the best among all the respondents. The service and sales has the best performance possibly because the 
need for propaganda their own services and products on the Internet has elaborated their knowledge levels.

\section{Conclusions and discussion}

There are several contributions of this paper. First of all, for the first time, the study conducted a survey on the third digital divide in two major cities in China. Previous studies either focused in just one location or region. In this study however, we extend the research to two different regions, compared and contrasted their difference.

Secondly, the study not only study the students in the university, who benefit most from the ICT development of China, but also the other people who might not doing well on computer and Internet, and still want to share more benefit from such development. One important finding in this aspect is that the third digital divide has a huge difference among different users. In addition, students' average performances are not the best, which otherwise would be assumed by many people in the past. The service and sales has the best performance possibly because the need for propaganda their own services and products on the Internet has elaborated their knowledge level.

Thirdly, regarding the factors that influence the third influence, we here propose a model (See Figure 1) that influences the third digital divide, especially via the mobile device. The third digital divide on mobile device is initiated from internet access via mobile phone. Such access is oriented by contents and topics, when accumulated with frequency of staying online, such gap would increase proportionally. The three factors are also associated with each other (indicated by the dash line arrows). In addition, the preexisting first and second digital divides continue to exert their influences on their counterpart in the third level.
The booming of mobile Internet has brought unprecedented opportunities to the Chinese society. People are offered with fast and convenient Internet access to seek the information at their own interests, making the knowledge sharing more easily. On the hands, however, how to accommodate those people who either disadopt at their own wills or unable embrace such technology for other reasons, inviting more people to share the expertise and knowledge, mitigating the preexisting information gap, is a huge challenge for the Chinese government.

Table 1. Reliability analysis of the questionnaire

\begin{tabular}{|c|c|c|c|c|}
\hline variable & item & $\begin{array}{c}\text { Corrected } \\
\text { Item-Total } \\
\text { Correlation }\end{array}$ & $\begin{array}{c}\text { Cronbach's } \\
\text { Alpha if } \\
\text { Item Deleted }\end{array}$ & $\begin{array}{c}\text { Cronbach's } \\
\alpha\end{array}$ \\
\hline \multirow{14}{*}{$\begin{array}{l}\text { Net } \\
\text { accessibility }\end{array}$} & NAC1 & .578 & .763 & \multirow{14}{*}{.766} \\
\hline & NAC 2 & .512 & .761 & \\
\hline & NAC 3 & .641 & .760 & \\
\hline & NAC 4 & .743 & .764 & \\
\hline & NAC 5 & .593 & .762 & \\
\hline & NAC 6 & .648 & .764 & \\
\hline & NAC 7 & .641 & .750 & \\
\hline & NAC 8 & .729 & .746 & \\
\hline & NAC 9 & .710 & .747 & \\
\hline & NAC 10 & .666 & .749 & \\
\hline & NAC 11 & .839 & .756 & \\
\hline & NAC 12 & .706 & .747 & \\
\hline & NAC 13 & .613 & .752 & \\
\hline & NAC 14 & .513 & .757 & \\
\hline \multirow{4}{*}{ Net Usage } & NUS 1 & .586 & .756 & \multirow{4}{*}{.780} \\
\hline & NUS 2 & .628 & .765 & \\
\hline & NUS 3 & .713 & .737 & \\
\hline & NUS 4 & .634 & .748 & \\
\hline \multirow{5}{*}{$\begin{array}{l}\text { Media } \\
\text { Choice }\end{array}$} & MCF 1 & .521 & .741 & \multirow{5}{*}{.755} \\
\hline & MCF 2 & .558 & .625 & \\
\hline & MCF 3 & .605 & .702 & \\
\hline & MCF 4 & .602 & .753 & \\
\hline & MCF 5 & .598 & .660 & \\
\hline \multirow{10}{*}{$\begin{array}{l}\text { Network } \\
\text { knowledge }\end{array}$} & NKW 1 & .714 & .841 & \\
\hline & NKW 2 & .729 & .883 & \\
\hline & NKW 3 & .682 & .860 & \\
\hline & NKW 4 & .690 & .844 & \\
\hline & NKW 5 & .761 & .844 & \\
\hline & NKW 6 & .640 & .846 & \\
\hline & NKW 7 & .746 & .846 & \\
\hline & NKW 8 & .710 & .866 & \\
\hline & NKW 9 & .715 & .840 & \\
\hline & NKW 10 & .639 & .838 & \\
\hline
\end{tabular}


Table 2. Linear regression between different variables

(Dependent variable: Internet knowledge)

\begin{tabular}{|c|c|c|c|}
\hline variable & item & $\begin{array}{c}\text { Beta } \\
\text { (Standard Coefficients) } \\
\text { Beijing } \\
\end{array}$ & $\begin{array}{c}\text { Beta } \\
\text { (Standard Coefficients) } \\
\text { Shanghai } \\
\end{array}$ \\
\hline \multirow{5}{*}{ Population } & Age & .055 & -.042 \\
\hline & Gender & .045 & -.047 \\
\hline & Monthly Income & -.130 & .003 \\
\hline & Education Degree & .088 & -.048 \\
\hline & Occupation & .143 & -.123 \\
\hline \multirow{14}{*}{ Net accessibility } & NAC 1 & .010 & .177 \\
\hline & NAC 2 & $.233 * * *$ & $.142 * * *$ \\
\hline & NAC 3 & .108 & .008 \\
\hline & NAC 4 & .002 & -.036 \\
\hline & NAC 5 & -.012 & .076 \\
\hline & NAC 6 & .079 & -.017 \\
\hline & NAC 7 & .103 & -.134 \\
\hline & NAC 8 & .197 & $.171 * * *$ \\
\hline & NAC 9 & -.113 & .036 \\
\hline & NAC 10 & .124 & .034 \\
\hline & NAC 11 & -.102 & -.033 \\
\hline & NAC 12 & -.080 & .170 \\
\hline & NAC 13 & -.085 & -.041 \\
\hline & NAC 14 & -.106 & .021 \\
\hline \multirow{4}{*}{ Net usage } & NUS 1 & .083 & $.094 * *$ \\
\hline & NUS 2 & -.120 & -.108 \\
\hline & NUS 3 & $-.210 * * *$ & -.005 \\
\hline & NUS 4 & .124 & .156 \\
\hline \multirow{5}{*}{ Media Choice } & MCF 1 & .236 & -.142 \\
\hline & MCF 2 & $.166^{* *}$ & -.010 \\
\hline & MCF 3 & .178 & $.066^{* *}$ \\
\hline & MCF 4 & $.134 * *$ & $.191^{* *}$ \\
\hline & MCF 5 & $.196^{* *}$ & .066 \\
\hline \multicolumn{2}{|c|}{ Adjusted R Square } & 0.669 & 0.584 \\
\hline
\end{tabular}

${ }^{*} \mathrm{p}<0.05, \quad * * \mathrm{p}<0.01, * * * \mathrm{p}<0.001$.

Table 3. Descriptive statistics of Internet knowledge score

Descriptive Statistics

\begin{tabular}{|l|c|c|c|c|c|c|c|}
\hline & $\mathrm{N}$ & Minimum & Maximum & Sum & Mean & Std.Deviation & Variance \\
\hline $\begin{array}{l}\text { Net knowledge } \\
(\mathrm{BJ})\end{array}$ & 260 & .00 & 22.00 & 1333.00 & 10.2538 & 4.27597 & 18.284 \\
\hline $\begin{array}{l}\text { Net Knowledge } \\
(\mathrm{SH})\end{array}$ & 258 & 2.00 & 23.00 & 1332.00 & 10.3256 & 4.13666 & 17.112 \\
\hline
\end{tabular}


Table 4. Result of Paired samples T test of Internet knowledge

Paired Samples Test

\begin{tabular}{|c|c|c|c|c|c|c|}
\hline & \multicolumn{3}{|c|}{ Paired Differences } & \multirow{2}{*}{$\mathrm{t}$} & df & Sig.(2-tailed) \\
\cline { 2 - 6 } & Mean & $\begin{array}{c}\text { Std. } \\
\text { Deviation }\end{array}$ & $\begin{array}{c}\text { Std. Error } \\
\text { Mean }\end{array}$ & Sean & & \\
\hline $\begin{array}{c}\text { Net knowledge (BJ) - } \\
\text { Net Knowledge (SH) }\end{array}$ & -.116 & 5.630 & .496 & -.235 & 257 & 815 \\
\hline
\end{tabular}

Table 5. Overall Comparison of Internet knowledge score among different users

\begin{tabular}{|l|l|l|}
\hline Occupation & $\begin{array}{l}\text { Percentage in the total } \\
\text { respondent }\end{array}$ & $\begin{array}{l}\text { Average personal score of the Internet } \\
\text { knowledge (23 of Maximal point) }\end{array}$ \\
\hline Students & $63.71 \%$ & 11.88 \\
\hline Government officials & $11.20 \%$ & 10.29 \\
\hline Professional Specialty & $9.65 \%$ & 11.24 \\
\hline Business management & $10.42 \%$ & 9.68 \\
\hline Service \& sales & $5.02 \%$ & 22.15 \\
\hline
\end{tabular}

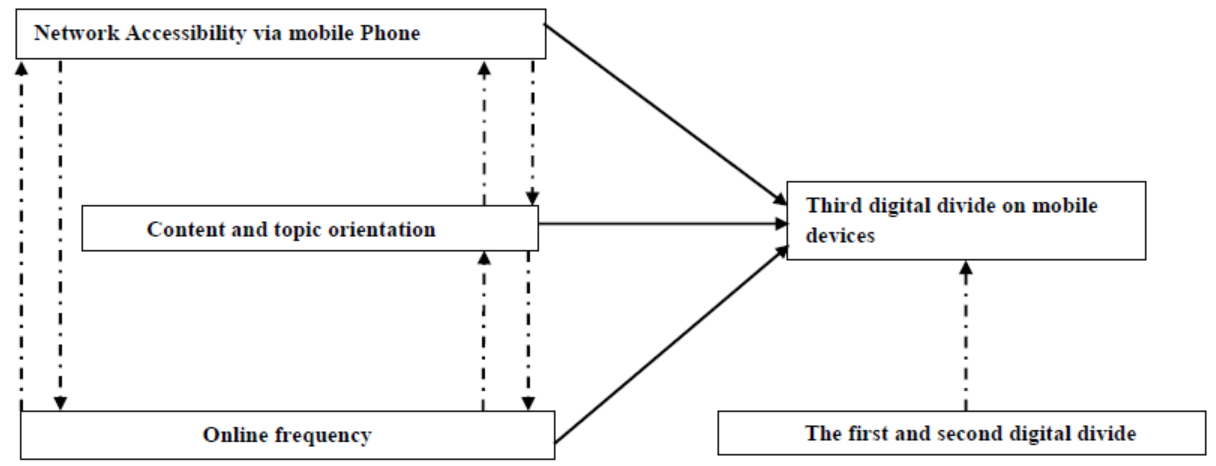

Fig.1: Conceptual model of the third digital divide on mobile devices in Beijing and Shanghai

\section{References}

[1] Attewell, P., The first and second digital divides. Sociology of Education, 74 (July), pp. 252-259, 2001

[2] Bucy, E.P., Social access to the Internet. Press/Politics, 5(1), $50-61,2000$

[3] Bunz, U., Generational comparison of gender, computer anxiety, and computer-email-web fluency. Studies in
Media and Information Literacy Education, 9(2).54-69, 2009

[4] Çiğdem Arıcıgil Çilana, Bilge Acar Bolata, Erman Coşkun, Analyzing digital divide within and between member and candidate countries of European Union. Government Information Quarterly, Volume 26, Issue 1, pp. 98-105, 2009 
[5] CNNIC, The statistic report on the 30th survey of the Internet development in China (in Chinese), Page 56, Retrieved July 19, 2012, Available at: http://www.cnnic.cn/research/bgxz/tjb g/201207/P020120719489935146937. pdf

[6] DiMaggio, P. and Hargittai, E., From the 'Digital Divide' to 'Digital Inequality': Studying Internet Use as Penetration Increases. Working Paper \#15, 2001, Princeton: Center for Arts and Cultural Policy Studies, Princeton University. Retrieved September 20, 2008, from

http://www.princeton.edu/ artspol/wo rkpap15.html;

[7] Ettema, James S. and Gerald F. Kline, Deficits, Differences, and Ceilings Contingent Conditions for Understanding the Knowledge Gap', Communication Research 2(4): pp.179202, 1977

[8] Katzman, N, The impact of communication technology: Promises and prospects. Journal of Communication, 24, pp.47-58, 1974

[9] Kingsley, P., and Anderson, T, Facing life without the Internet. Internet Research: Electronic Networking Applications and Policy, 8(4), pp.303 - 312, 1998

[10] María Rosalía Vicente and Ana Jesús López, Assessing the regional digital divide across the European Union-27, Telecommunications Policy, vol. 35, issue 3, pp. 220-237, 2011
[11] Morgan Stanley Alpha Wise, Umeng, Flurry Analytics, insidemobileapps.com, computerworld.com, Apple, Stenvall Skoeld \& Company analysis, 2011). Available at: http://www.stenvallskoeld.com/1579/china-iphone-ipadanalysis

[12] Sanjeev Dewan and Frederick J. Riggins., The digital divide: current and future research directions, Journal of the Association for Information Systems, Vol. 6, No. 12. pp. 298-337, 2005

[13] Tichenor, P. J., Donohue, G. A., and Olien, C. N., Mass media flow and differential growth in knowledge. Public Opinion Quarterly, 34(2), pp. 159-170, 1970

[14] Timothy Bresnahan and Manuel Trajtenberg., General Purpose Technologies, Engines of Growth, Journal of Econometrics, Vol. 65(1), pp. 83-108, 1995

[15] Van Dijk, J., and Hacker, K., The digital divide as a complex and dynamic phenominon. The Information Society, 19, pp.315-326, 2003

[16] Wei, L., and Zhang, M., The third digital divide: The knowledge gap on the Internet. Journalism \& Communication, 13 (4), 43-53, 2006 